\title{
Using Age and Weight Specific CT Protocol to Estimate Reference Effective Dose to Patients Undergoing CT Examination Issahaku Shirazu', Y. B Mensah ${ }^{2}$, Cyril Schandorf ${ }^{3}$, S. Y. Mensah ${ }^{4}$
}

\author{
${ }^{1}$ University of Cape Coast, School of Agriculture and Physical Sciences Faculty of Physical Sciences, Department of Physics, \\ Cape coast, Ghana \\ ${ }^{2}$ University of Ghana Medical School, Department of Radiology, Korle-Bu Teaching Hospital, Accra Ghana \\ ${ }^{3}$ Graduate School of Nuclear and Allied Sciences, University of Ghana, Legon, Ghana \\ ${ }^{4}$ University of Cape Coast, School of Agriculture and Physical Sciences, Faculty of Physical Sciences, Department of Physics \\ Cape Coast, Ghana
}

\begin{abstract}
In x-ray computed tomography (CT), the most common parameters used to estimate and minimize patient dose is the CT dose index (CTDI) and DLP. The aim of the study is to serve as a reference values during QC for the purposes of QA in other to reduce doses to patients undergoing CT scan using the age and weight specific CT protocol set out by various manufacturers and other international organizations. This was done by recording CTDI and DLP values to patients within a specific age and weight bracket during scanning on the scanning console and on image data. The effective dose values represents an averaged dose to patients, hence the measurements are only an approximation of the dose to patient, these doses may be overestimated or underestimated by a factor of two or more with CTDI and DLP values in comparison with point dose values. CTDI and DLP were used to evaluate CT scanner output and estimating patient regional effective dose in this study. The estimated head CTDI scans base on the various protocol from all the hospitals increase from approximately $2.8 \mathrm{mGy}$ in newborns to approximately $8.7 \mathrm{mGy}$ in adults. Resulting with a variation of effective dose from $0.67 \mathrm{mSv}$ in new born to approximately $1.03 \mathrm{mSv}$ in oversize adults. Neonates head CT effective doses are higher than those for the normal adults except oversize adults as shown in Table 4.4. The chest, abdominal and pelvis CTDI values increases from 2.8, 2.5 and $2.7 \mathrm{mGy}$ in neonates of approximately $3.4 \mathrm{~kg}$ of weight to $19.84,7.78$ and $11.33 \mathrm{mGy}$ in adults of approximately $72.5 \mathrm{~kg}$ of weight respectively. The estimated effective doses for neonates undergoing chest, abdomen and pelvis of the body CT were $0.83,6.7,4.87$ and $5.52 \mathrm{mSv}$, whereas those for normal-sized adults are 13.31, 4.61 and $5.34 \mathrm{mSv}$ respectively. Chest oversize patients' examinations exceeded the recommended dose levels of $19.84 \mathrm{mSv}$ whiles the head, abdomen and pelvis were: $1.03,7.16$ and $5.98 \mathrm{mSv}$ respectively. It was concluded that patient body doses could be substantially minimized through careful selection of scanning parameters based on clinical indications of study, patient age, body size, and body region being examined. Additional dose reduction to superficial body regions would require the use of shielding materials.
\end{abstract}

Keywords: Paediatric Dose, Effective Dose, Abdomen, Pelvic, CTDI, Specific CT Protocol, Organ Dose, DLP

\section{INTRODUCTION}

Radiation dose in x-ray computed tomography (CT) is typically measured by using a simple cylindrical phantom and expressed as either weighted-CTDI $\left(\mathrm{CTDI}_{\mathrm{W}}\right)$ OR a volume-averaged $\mathrm{CT}$ dose index $\left(\mathrm{CTDI}_{\mathrm{V}}\right)$. However, the more realistic and practical way to measure this quantity in addition to the Phantom study is to record the $\mathrm{CTDI}_{\mathrm{V}}$ values from the console during imaging over a considerable period and perform clinical audit to see its consistence and compare with the QC values on the phantom study.

Furthermore, understanding the methods for quantifying radiation dose is important for users of this technology. As compared to other modalities, CT delivers considerably more dose to the patient [1]. Also, other modalities like the conventional radiography which uses a screen-film radiograph when exposed to too much radiation, the film is overexposed and gives a visual 
indication of excessive patient dose. Conversely, CT images never look overexposed, as CT provides an image of normalized tissue attenuation values, this exactly lay the danger as this may not be detected over considerable period. Also, image noise is reduced if radiation is increased; consequently, a CT image looks fine and much better if excessive radiation is used [2]. Thus, without dose measurements, the CT user lacks the visual clues needed to appropriately adjust the tube current-time product or tube potential in order to avoid excessive patient dose [3]. In computed and digital radiography, the situation is similar to $\mathrm{CT}$; overexposure will reduce image noise and can happen without the operator being aware, as radiologists do not often complain about image noise being too low.

In general, clinical CT examinations involve exposures from multiple rotations of the $\mathrm{x}$-ray source, such that the dose to the irradiated volume is the accumulated dose from the adjacent scans [4]. One term used to describe this accumulated dose is the multiple scan average dose (MSAD), which as its name implies, is the dose from a multiple scan examination, averaged over one scan interval in the central portion of the multiple-scan dose profile [5]. The MSAD required substantial time to make the measurement due to the tedious nature of calibration, handling, and reading and as such was not used [5].

In 1981, Shoppe et al [6] introduced the concept of CTDI, defining it as the integral of the single scan radiation dose profile along the $\mathrm{z}$ axis, normalized to the thickness of the imaged section ("slice thickness"). They showed that with corrections for scan spacing, the CTDI can estimate MSAD in a standardized, convenient manner. Thus, the more easily measured ionization chamber-based CTDI became the predominant method of measuring radiation dose from a CT system [5].

\section{A. Objective}

The purpose of our study was to measure dose parameters to determine typical reference effective dose to patients undergoing $\mathrm{CT}$ examination base on the age and weight specific $C T$ protocol of adult and pediatric patients undergoing a single $\mathrm{CT}$ examination using manufacturer protocol, professional and regulatory organizations, including the International Commission on Radiological Protection (ICRP), American College of Radiology (ACR), American Association of Physicists in Medicine (AAPM), International Atomic Energy Agency (IAEA), and European Commission (EC) guidelines.

\section{B. Basic Principles}

To measure the CTDI in this study using radiation dose from a single CT scan is by recording the CTDIvol of the various age groups on the imaging console over a period and then the integrated dose is normalized to the nominal beam width. Hence, CTDI in this study is not a dose to a point, but rather an average dose over a volume [7]. Although CTDI is measured by using a single scan, it can be used to estimate the average dose from multiple scans where the table is incremented between successive tube rotations (ie, the MSAD) [5]. In contrast, for scans such as perfusion CT where the table is not incremented during the examination, the CTDI is a poor descriptor of dose, and a point dose measurement is more appropriate [8]. When a CTDI is measured over a given length it is term as dose length product (DLP).

Mathematically $\mathrm{CTDI}_{\mathrm{V}}$ is express as:

$$
C T D I_{V O L}=\frac{1}{N . T} \int_{-\infty}^{\infty} D(Z) d z
$$

Where;

$\mathrm{D}(\mathrm{z})=$ the radiation dose profile along the $\mathrm{z}$-axis, $\mathrm{N}=$ the number of slice in a single axial scan.

$\mathrm{T}=$ the width/slice thickness of the tomographic section along the z-axis.

The standard S.I unit for CTDI is the mGy.

In addition the MSAD is express mathematically as:

$$
M S A D=\frac{T}{I} C T D I
$$

where $\mathrm{T}$ is the slice thickness and $I$ the increment between successive slices.

The standard unit for the MSAD is the mGy.

Finally, DLP, which includes the irradiated volume and represents the overall exposure for an examination and is calculated as:

$$
D L P=C T D I_{V O L} * L
$$


In literature a number of publication has been done in an attempt to determine absorbed dose to patients undergoing CT examination. However, all this publication are centered on either adult and or paediatric patients' protocol and therefore limited in scope $[9,10$, $11,12]$. In an attempt to expand the scope this study relayed on both age and weight specific protocol to determine the effective dose to patients. Some of the available publication include estimate of absorbed dose to paediatric patients in Ghana by inkoom et al [9] and Patient Radiation Doses from Adult and Pediatric CT by Walter Huda1and Awais Vance [10]

The effective dose is define as the product of the regionspecific normalizing constant $\left(\mathrm{E}_{\mathrm{DLP}}\right)$ and the dose length product (DLP).

Define mathematically as:

$$
\mathrm{E}=\mathrm{E}_{\mathrm{DLP}} * \mathrm{DLP}
$$

Various regional effective doses are estimated using the region-specific normalizing constant in table 1.1.

Table 1. Dose Estimate Parameters

\begin{tabular}{|l|l|l|l|l|l|}
\hline $\begin{array}{l}\text { CT } \\
\text { examinations }\end{array}$ & $\begin{array}{l}\text { DLP } \\
\text { mGy cm }\end{array}$ & $\begin{array}{l}\text { CTDI }_{W} \\
\mathrm{mGy}\end{array}$ & $\begin{array}{l}\text { CTDIvol } \\
\mathrm{mGy}\end{array}$ & $\begin{array}{l}\text { Typical Effective } \\
\text { Dose values mSv }\end{array}$ & $\begin{array}{l}\text { EDLP } \\
\mathrm{mSv}_{\mathrm{mGy}} \mathrm{cm}^{-1}\end{array}$ \\
\hline Head CT & 1050 & 60 & 73.80 & $1-2$ & 0.0023 \\
\hline Chest CT & 650 & 30 & 36.90 & $5-7$ & 0.017 \\
\hline Pelvis CT & 570 & 35 & 43.05 & $3-4$ & 0.019 \\
\hline Abdomen CT & 780 & 35 & 43.05 & $5-7$ & 0.016 \\
\hline $\begin{array}{l}\text { Abdomen- } \\
\text { Pelvis CT }\end{array}$ & & & & $8-14$ & 0.015 \\
\hline Kidney & & & & $\begin{array}{l}1-3 \\
\text { (renal dose) }\end{array}$ & $\begin{array}{l}0.0086 \text { (normalized } \\
\text { renal dose factor) }\end{array}$ \\
\hline
\end{tabular}

Table 2. Age and region-specific normalizing constant

\begin{tabular}{|l|l|l|l|l|}
\hline Age & $\mathrm{E}_{\text {DLP H }}$ & $\mathrm{E}_{\text {DLPC }}$ & $\mathrm{E}_{\text {DLP A }}$ & $\mathrm{E}_{\text {DLP P }}$ \\
\hline & Head & Chest & Abdomen & Pelvis \\
\hline Years & $\mathrm{mSV} / \mathrm{mGy} \mathrm{cm}$ & $\mathrm{mSv} / \mathrm{mGy} \mathrm{cm}$ & $\mathrm{mSv} / \mathrm{mGy} \mathrm{cm}$ & $\mathrm{mSV} / \mathrm{mGy} \mathrm{cm}$ \\
\hline New born & 0.0085 & 0.0706 & 0.0804 & 0.0672 \\
\hline $1 \mathrm{y}$ & 0.0053 & 0.0467 & 0.0514 & 0.0431 \\
\hline $5 \mathrm{y}$ & 0.0035 & 0.0314 & 0.0349 & 0.0294 \\
\hline $10 \mathrm{y}$ & 0.0027 & 0.0234 & 0.0246 & 0.0216 \\
\hline$>18$ & 0.0019 & 0.0145 & 0.0153 & 0.0129 \\
\hline
\end{tabular}

\section{A. Material}

The materials used is shown in table 3.1 and figure 3.13.4

Table 1. Specifications of CT scanners

\begin{tabular}{|l|l|}
\hline Manufacturer & Scanner model/scan mode \\
\hline Philips Brilliance 64 & Biilliance 64, multi slice, axial and helical modes \\
\hline Siemens Emotion 16 & Emotion 16, multi slice, axial and helical modes \\
\hline GE Lightspeed VCT 64 & Lightspeed VCT 64, multi slice axial and helical modes \\
\hline Toshiba Aquilion ONE & Aquilion ONE, multi slice, axial and helical modes \\
\hline
\end{tabular}

The various scanners are shown in figure 3.1 to 3.4 ;

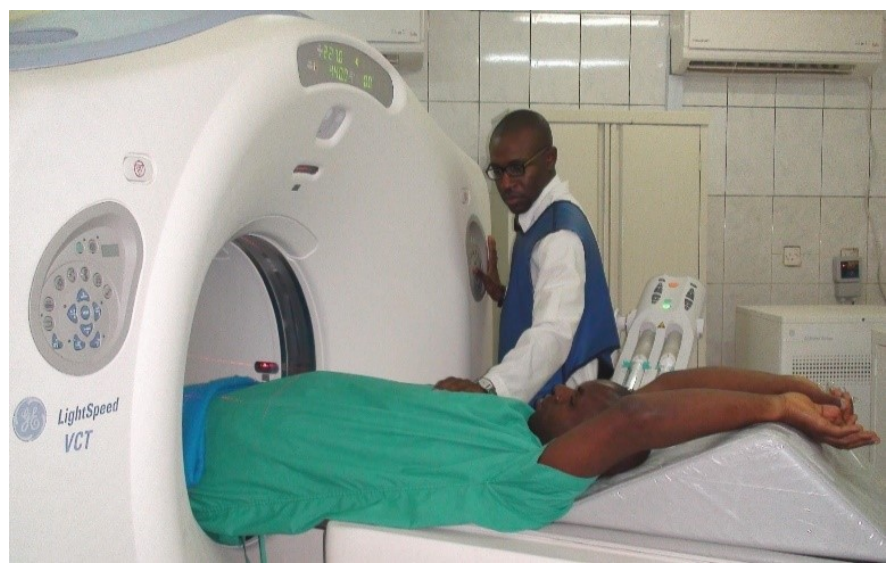

Figure 1. GE Medical Systems

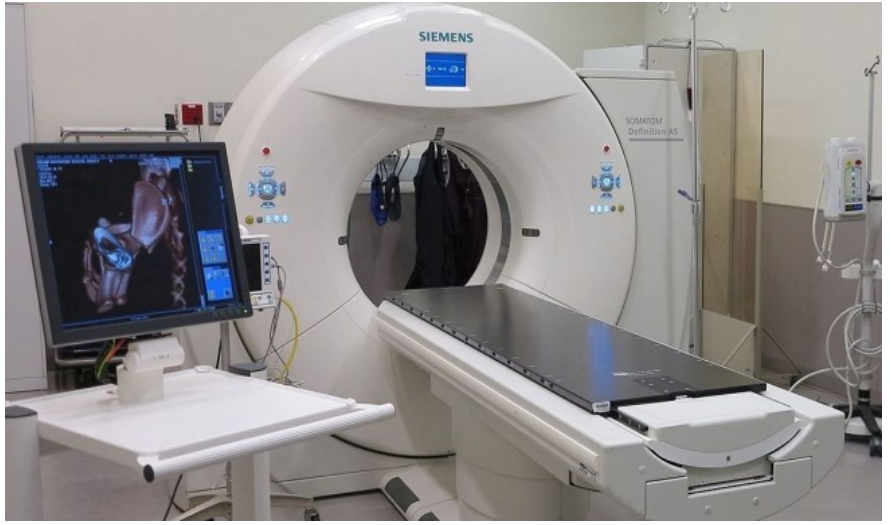

Figure 2. Siemens Medical Systems 


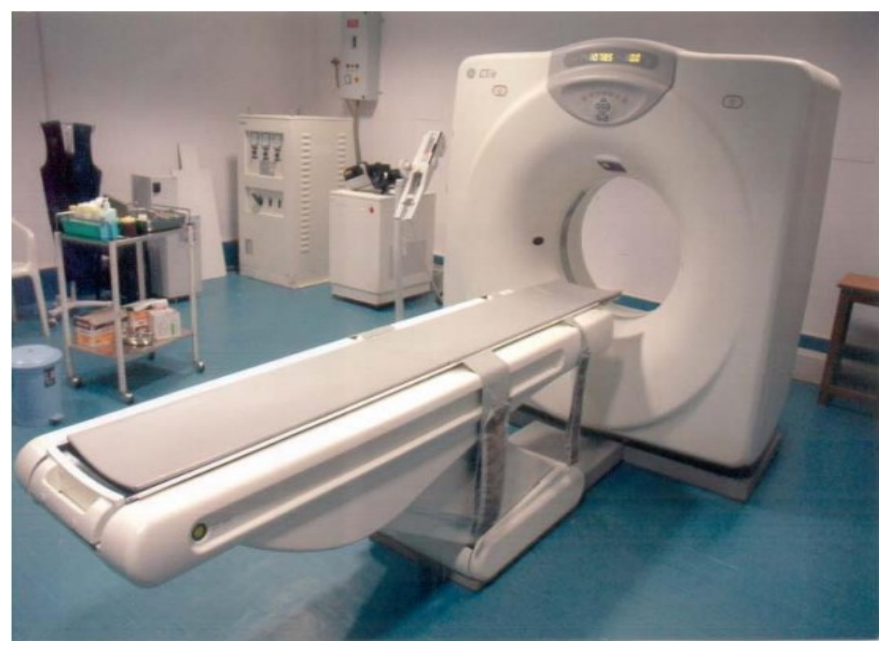

Figure 3. Philip Medical Systems

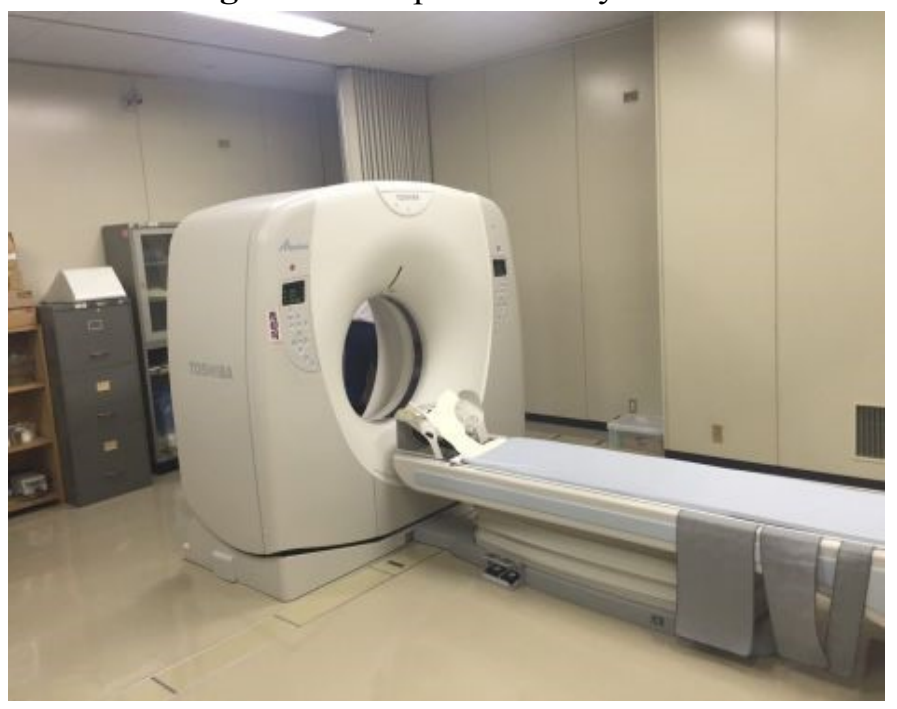

Figure 4. Toshiba medical System

\section{B. Methods}

The heads, chests, pelvic and abdomens of patients ranging from neonates to oversized adults $(3.5-120 \mathrm{~kg})$ were obtain from the scanning console directly and on image data during $\mathrm{CT}$ examination taken into account the patient age and weight protocol from the manufacturer of the various scanner type and the actually protocol in use. Furthermore, patient doses parameters (CTDI and DLP) were obtained for scanning protocols that were used taken into account the age and weight of the patient being scanned by typical MDCT scanners.

To estimate the effective dose, DLP and DLP conversion factor $\left(\mathrm{E}_{\mathrm{DLP}}\right)$ as developed by ICRP in ICRP Publication 103 as shown below were used.

$$
\text { Effective Dose }=E_{D L P} D L P
$$

where $\boldsymbol{E}_{\boldsymbol{D} L \boldsymbol{P}}$ varies from 0.0804 to 0.0153 in neonates to adults and describe as the abdominal conversion factor from ICRP publication 103 as stated in literature. This is because the effective dose is not measured but it is theoretical calculated dose based on the organs exposed by the applied radiation multiplied by tissueweighting factors. Because the tissue-weighting factors can change with new data and continuing analysis of existing data, the effective dose conversion factor estimates can change over time.

\section{RESULTS AND DISCUSSION}

\section{A. Results}

\section{Data Presentation}

Table 3. Weight and CDTI/DLP protocol

\begin{tabular}{|l|l|l|l|l|l|l|l|l|}
\hline Weight & $\begin{array}{l}\text { CDTI } \\
\text { Head }\end{array}$ & $\begin{array}{l}\text { DLP } \\
\text { Head }\end{array}$ & $\begin{array}{l}\text { CTDI } \\
\text { Chest }\end{array}$ & $\begin{array}{l}\text { DLP } \\
\text { Chest }\end{array}$ & $\begin{array}{l}\text { CTDI } \\
\text { Abdomen }\end{array}$ & $\begin{array}{l}\text { DLP } \\
\text { Abdomen }\end{array}$ & $\begin{array}{l}\text { CTDI } \\
\text { Pelvic }\end{array}$ & $\begin{array}{l}\text { DLP } \\
\text { Pelvic }\end{array}$ \\
\hline $\mathbf{k g}$ & $\mathbf{m G y}$ & $\mathbf{m G y - c m}$ & $\mathbf{m G y}$ & $\begin{array}{l}\mathbf{m G y -} \\
\mathbf{c m}\end{array}$ & $\mathbf{m G y}$ & mGy-cm & mGy & mGy-cm \\
\hline $0-6$ & 2.8 & 98 & 2.5 & 95 & 2.7 & 60.6 & 2.7 & 82.2 \\
\hline $7-10$ & 3.6 & 103 & 3.8 & 141.6 & 3.2 & 72 & 3.4 & 111.2 \\
\hline $11-15$ & 4.3 & 133.1 & 3.9 & 193.5 & 3.8 & 123 & 4.1 & 151 \\
\hline $15-20$ & 4.8 & 140.8 & 4.5 & 270 & 4.6 & 151.4 & 4.6 & 199.2 \\
\hline $21-50$ & 4.9 & 187.2 & 5.2 & 334.4 & 4.9 & 206.4 & 4.9 & 280 \\
\hline $51-70$ & 5.9 & 310.8 & 7.4 & 487.2 & 5.1 & 262 & 5.1 & 362 \\
\hline $71-90$ & 7.1 & 352.3 & 7.5 & 918 & 6.7 & 301.4 & 6.8 & 413.6 \\
\hline$>90$ & 8.7 & 541.8 & 14.2 & 1368 & 9.5 & 468 & 11.3 & 463.2 \\
\hline
\end{tabular}

Table 4. Age and CTDI/DLP protocol

\begin{tabular}{|l|l|l|l|l|l|l|l|l|}
\hline Age & $\begin{array}{l}\text { CDTI } \\
\text { Head }\end{array}$ & $\begin{array}{l}\text { DLP } \\
\text { Head }\end{array}$ & $\begin{array}{l}\text { CTDI } \\
\text { Chest }\end{array}$ & $\begin{array}{l}\text { DLP } \\
\text { Chest }\end{array}$ & $\begin{array}{l}\text { CTDI } \\
\text { Abdomen }\end{array}$ & $\begin{array}{l}\text { DLP } \\
\text { Abdomen }\end{array}$ & $\begin{array}{l}\text { CTDI } \\
\text { Pelvic }\end{array}$ & $\begin{array}{l}\text { DLP } \\
\text { Pelvic }\end{array}$ \\
\hline Years & $\mathrm{mGy}$ & $\begin{array}{l}\mathrm{mGy-} \\
\mathrm{cm}\end{array}$ & $\mathrm{mGy}$ & $\begin{array}{l}\mathrm{mGy-} \\
\mathrm{cm}\end{array}$ & $\mathrm{mGy}$ & mGy-cm & $\mathrm{mGy}$ & $\mathrm{mGy-cm}$ \\
\hline New born & 2.8 & 98 & 2.5 & 95 & 2.7 & 60.6 & 2.7 & 82.2 \\
\hline $6 \mathrm{~m}$ & 3.6 & 103 & 3.8 & 141.6 & 3.2 & 72 & 3.4 & 111.2 \\
\hline $1 \mathrm{y}$ & 4.3 & 133.1 & 3.9 & 193.5 & 3.8 & 123 & 4.1 & 151 \\
\hline $2-4 \mathrm{y}$ & 4.8 & 140.8 & 4.5 & 270 & 4.6 & 151.4 & 4.6 & 199.2 \\
\hline $5-10 \mathrm{y}$ & 4.9 & 187.2 & 5.2 & 334.4 & 4.9 & 206.4 & 4.9 & 280 \\
\hline $11-18 \mathrm{y}$ & 5.9 & 310.8 & 7.4 & 487.2 & 5.1 & 262 & 5.1 & 362 \\
\hline$>18$ & 7.1 & 352.3 & 7.5 & 918 & 6.7 & 301.4 & 6.8 & 413.6 \\
\hline oversize & 8.7 & 541.8 & 14.2 & 1368 & 9.5 & 468 & 11.3 & 463.2 \\
\hline
\end{tabular}

Table 5. Variation of Dose parameters with Age

\begin{tabular}{|l|r|l|l|l|}
\hline Age & $\mathbf{E}_{\boldsymbol{H}}$ & $\mathbf{E}_{\boldsymbol{C}}$ & $\mathbf{E}_{\boldsymbol{A}}$ & \multicolumn{1}{l|}{$\mathbf{E}_{\mathbf{P}}$} \\
\hline & Head & \multicolumn{1}{l|}{ Chest } & \multicolumn{1}{l|}{ Abdomen } & \multicolumn{1}{l|}{ Pelvis } \\
\hline Years & \multicolumn{1}{l|}{$\mathrm{mSv}$} & $\mathrm{mSv}$ & $\mathrm{mSv}$ & $\mathrm{mSv}$ \\
\hline New born & 0.833 & 6.707 & 4.87224 & 5.52384 \\
\hline $6 \mathrm{~m}$ & 0.8755 & 9.99696 & 5.7888 & 7.47264 \\
\hline $1 \mathrm{y}$ & 0.70543 & 9.03645 & 6.3222 & 6.5081 \\
\hline $2-4 \mathrm{y}$ & 0.74624 & 12.609 & 7.78196 & 8.58552 \\
\hline $5-10 \mathrm{y}$ & 0.6552 & 10.50016 & 7.20336 & 8.232 \\
\hline $11-18 \mathrm{y}$ & 0.83916 & 11.40048 & 6.4452 & 7.8192 \\
\hline$>18$ & 0.66937 & 13.311 & 4.61142 & 5.33544 \\
\hline oversize & 1.02942 & 19.836 & 7.1604 & 5.97528 \\
\hline
\end{tabular}


Table 6. Variation of Dose parameters with Weight

\begin{tabular}{|c|c|c|c|c|}
\hline Weight & $\mathbf{E}_{\mathrm{H}}$ & $\mathbf{E}_{\mathrm{C}}$ & $\mathbf{E}_{\mathbf{A}}$ & $\mathbf{E}_{\mathbf{P}}$ \\
\hline & Head & Chest & Abdomen & Pelvis \\
\hline kg & $\mathbf{m S v}$ & $\mathbf{m S v}$ & $\mathbf{m S v}$ & $\mathbf{m S v}$ \\
\hline $0-6$ & 0.833 & 6.707 & 4.87224 & 5.52384 \\
\hline $7-10$ & 0.8755 & 9.99696 & 5.7888 & 7.47264 \\
\hline $11-15$ & 0.70543 & 9.03645 & 6.3222 & 6.5081 \\
\hline $15-20$ & 0.74624 & 12.609 & 7.78196 & 8.58552 \\
\hline $21-50$ & 0.6552 & 10.50016 & 7.20336 & 8.232 \\
\hline $51-70$ & 0.83916 & 11.40048 & 6.4452 & 7.8192 \\
\hline $71-90$ & 0.66937 & 13.311 & 4.61142 & 5.33544 \\
\hline$>90$ & 1.02942 & 19.836 & 7.1604 & 5.97528 \\
\hline
\end{tabular}

\section{Graphical Presentation}

The graphical presentation showing the relationship between CTDI, Effective dose, patients' age and weight.

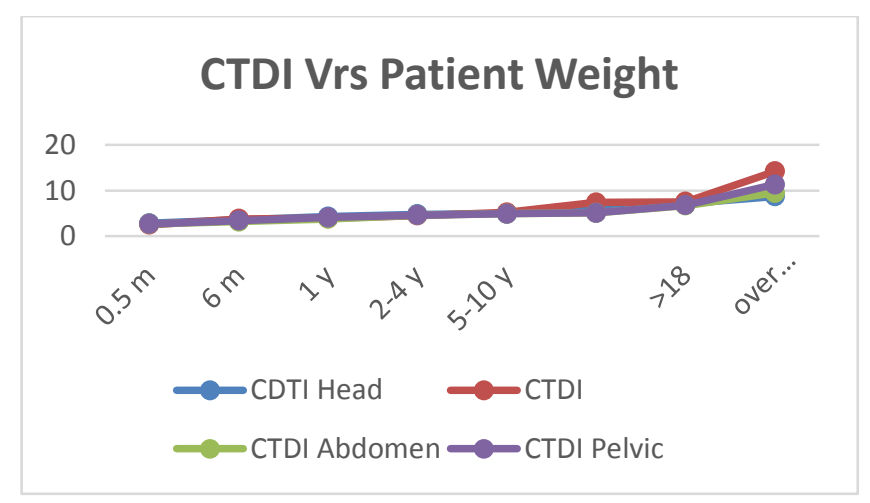

Figure 5. CTDI Vrs Patient Weight

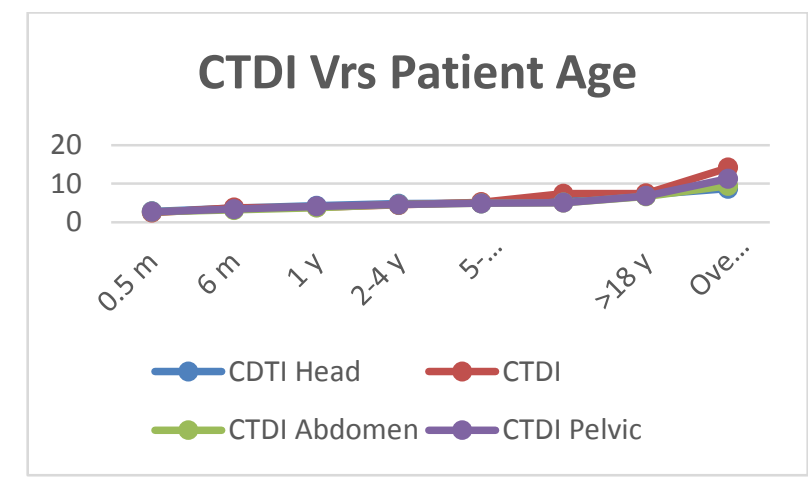

Figure 6. CTDI Vrs Patient Age

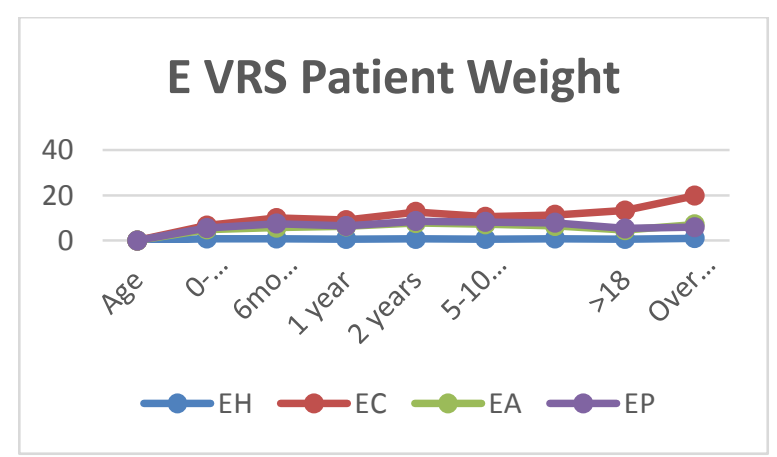

Figure 7. Effective dose VRS Patient Weight

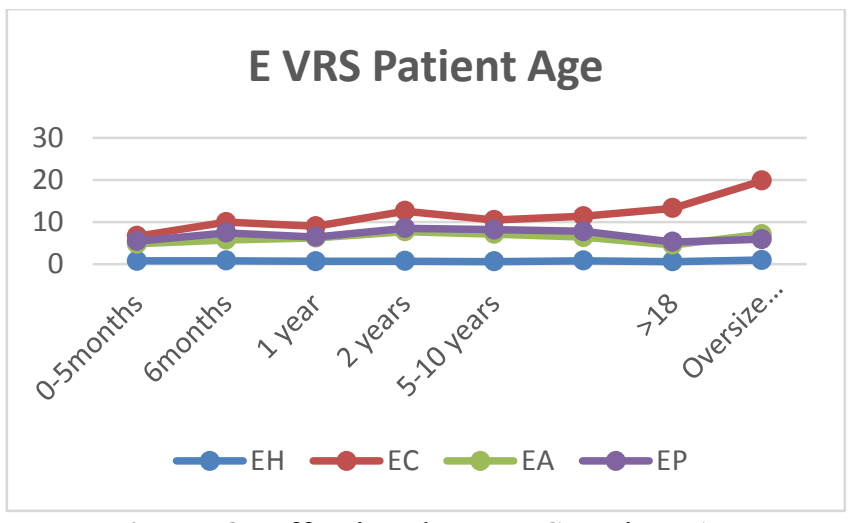

Figure 8. Effective dose VRS Patient Age

\section{Discussions}

Two reference dose parameters are commonly used for CT dose estimates in order to promote the use of good technique during CT imaging include; CTDI and DLP. CTDI is measured as weighted CTDI $\left(\mathrm{CTDI}_{\mathrm{w}}\right)$ or volume CTDI $\left(\mathrm{CTDI}_{\mathrm{vol}}\right)$. Both CTDI and DLP parameters are used for head, chest, abdomen and pelvis CT dosimetry which is an appropriate to the type of examination. In addition it provides control on the selection of exposure setting, such as mAs and voltage. DLP also provide control on the volume of irradiated area and the overall total exposure for an examination. They can be used for both helical scanning and serial scanning of head and other body examinations.

Clinically, current available scanners, function optimally between $125-200 \mathrm{mAs}$ and $80-120 \mathrm{kV}$ peak voltage, at various variations of age and weight as the X-ray exposure and tube voltage respectively. The estimated $\mathrm{CTDI}_{\mathrm{VOL}}$ values during head CT examination increase from approximately $2.8 \mathrm{mGy}$ in newborns to $8.7 \mathrm{mGy}$ in adults. Whiles the chest examination increases from $2.5 \mathrm{mGy}$ in neonates to $14.2 \mathrm{mGy}$ in adults. In addition, abdominal examination increases from $2.7 \mathrm{mGy}$ to $9.5 \mathrm{mGy}$ whiles pelvis examination increases from $2.7 \mathrm{mGy}$ to $11.3 \mathrm{mGy}$ in newborn to adults respectively. Patients weighing less than $10 \mathrm{~kg}$ receive body $\mathrm{CTDI}_{\mathrm{vol}}$ of $4.3 \mathrm{mGy}$, which is a factor of 2 less than for adults of more than $90 \mathrm{~kg}$.

Furthermore, the estimated effective dose varies from a minimum of $0.833,6.707,4.87224$ and 5.52384 for neonates' to1.02942, 5.97528, 7.1604 and 19.836 for head, chest, abdomen and pelvis of adults respectively, within the age bracket of $3.5 \mathrm{~kg}$ to $72.5 \mathrm{~kg}$. All the 
determined dose parameters met the recommendations of Ghana Nuclear regulatory authorities and all the professional and regulatory organizations, including the International Commission on Radiological Protection (ICRP), American College of Radiology (ACR), American Association of Physicists in Medicine (AAPM), International Atomic Energy Agency (IAEA), and European From the graphical representations in figure 4.1 to figure 4.4 both age and weight protocols as designed by various CT centers, which results in an increase in dose parameter. However, this corresponding increases is pronounced with $\mathrm{CTDI}_{\mathrm{vol}}$ with less pronounce with effective dose. Even though both parameters increases with increasing age and weight.

\section{CONCLUSION AND RECOMMENDATION}

Comparism of the performance against the criteria for each particular type of examination requires assessment of the values of the reference dose quantities associated with the technique typically used when scanning a standard-sized adult patients. In the absence of a welldefined scanning protocol, typical dosimetric practice should be determined on the basis of the mean results derived for a sample of at least 10 patients for each procedure. Despite the increasing attention on paediatric CT, specific tools for dose assessment for this particular application presently remain underdeveloped. Hence, the estimated reference CTDIvol, and DLP values are available for use.

In addition, the comparism of performance against reference dose value, there is sometimes a need to assess effective dose using ICRP Publication 103 for CT procedure. Effective dose are used mainly to assess a particular scanning protocol, which are estimated from DLP measured values, hence it has been estimate for use.

\section{ACKNOWLEDGEMENTS}

My sincere thanks goes to the entire staff of the Medical Radiation Physics Centre, Radiological and Medical Sciences Research Institute of Ghana Atomic Energy Commission, Department of Radiology, Korle-Bu Teaching Hospital, Tamale Teaching Hospital, Komfo Anokye Teaching Hospital, Cocoa clinic and 37 Military Hospital, for their support and cooperation.

\section{REFERENCES}

[1]. United Nations Scientific Committee on Effects of Radiation Atomic Radiation (UNSCEAR). Sources and effects of ionizing radiation report to the general assembly. New York: United Nations; 2000.

[2]. International Atomic Energy Agency (IAEA). Protection of patients in diagnostic and intervention radiology, nuclear medicine and radiotherapy. Proceeding of International Conference, Malaga, Spain, 26-30 March 2001; Vienna.

[3]. International Commission on Radiological Protection (ICRP). Managing patient dose in computed tomography annals of ICRP publication $87 ; 30(4)$. Oxford: Pergamon Press; 2000.

[4]. Muhogora WE, Nyanda AM, Lema US, Ngaile JE. Typical radiation doses to patients from some common x-ray examinations in Tanzania. Radiat Prot Dosim. 1999;82(4):301-305.

[5]. Brenner DV, Elliston CD, Hall EJ, Berdon WE. Estimated risks of radiation fatal cancer from paediatric CT. Am J Roentgenol. 2001; 176:289-296.

[6]. European Commission. European guidelines on quality criteria for computed tomography EUR 16262 EN, Luxemburg. Office for Official Publications of the European Communities; 1999.

[7]. Jessen KA, Shrimpton PC, Geleijns J, Panzer W, Tosi G. Dosimetry for optimisation of patient protection in CT. Appl Radiat Isot. 1999; 50:165-172.

[8]. International Electrotechnical Commission (IEC). Medical electrical equipment. Part 2-44: Particular requirements for the safety of $\mathrm{X}$-ray equipment or computed tomography. IEC 60601-2-44. Geneva, Switzerland; 1999.

[9]. Huda W, Scalzetti EM, Roskopf M. Effective dose to patients undergoing thoracic computed tomography examinations. Med Phys. 2000; 27(5):835-844.

[10]. Nishizawa K, Maruyama T, Takayama M, Okada M, Hachiya J, Furuya Y. Determination of organ doses and effective dose equivalents from computed tomographic examination. Br J Radiol. 1991; 64:20-28.

[11]. Donnelly LF, Emery KH, Brody AS, et al. Minimizing radiation dose for paediatric body applications of singledetector helical CT. Am J Roentgenol. 2001; 176:303-306.

[12]. Starck G, Lonn L, Cederblad A, Forssell-Aronsson E, Sjostrom L, Alpsten M. A method to obtain the same levels of CT image noise for patients of various sizes to minimize radiation dose. Br J Radiol. 2002; 75:140150. 